
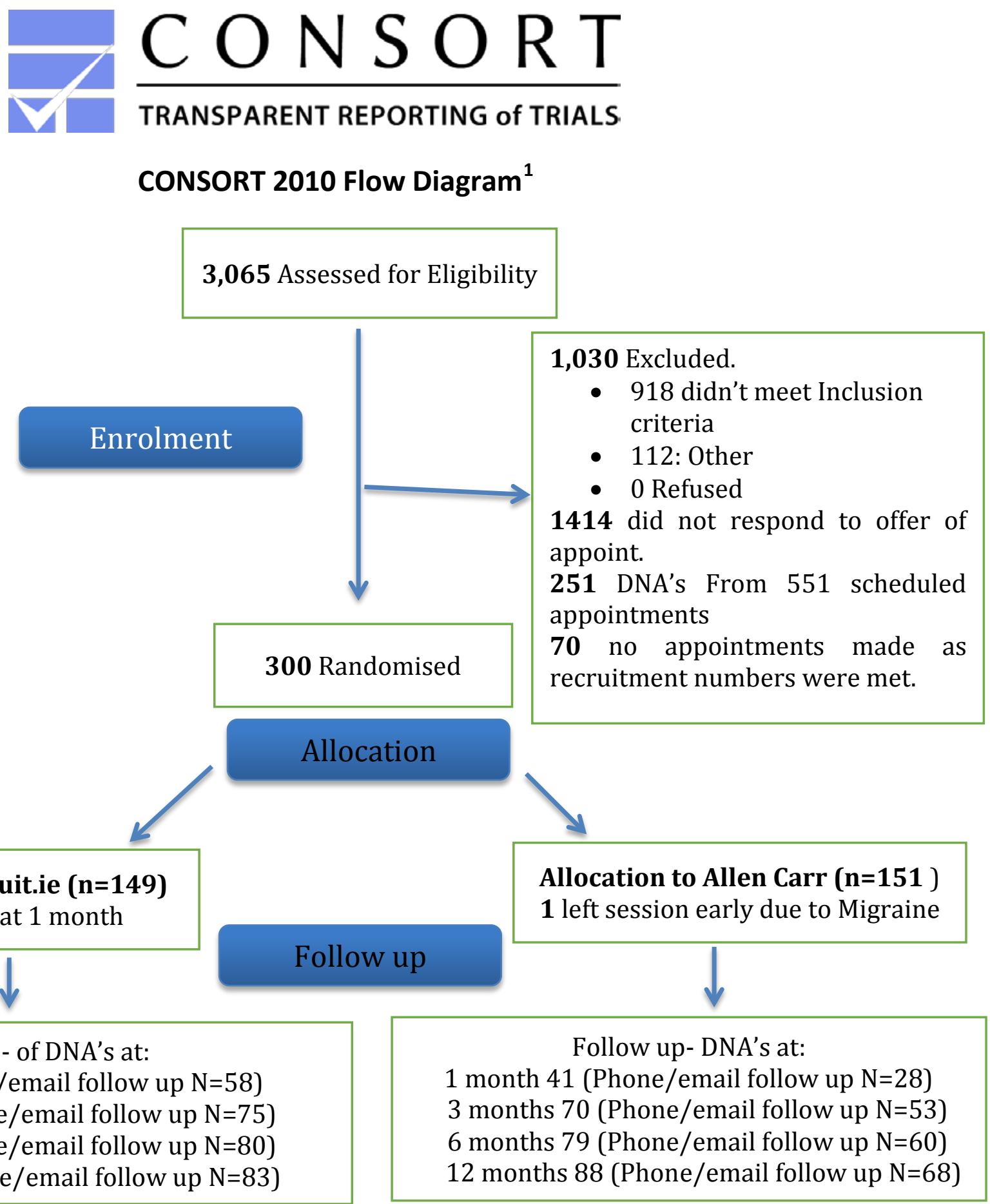

Follow up- of DNA's at:

1 month 80 (Phone/email follow up $\mathrm{N}=58$ )

3 months 103 (Phone/email follow up $\mathrm{N}=75$ )

6 months 108 (Phone/email follow up $\mathrm{N}=80$ )

12 months 111(Phone/email follow up $\mathrm{N}=83$ )
1,030 Excluded.

- 918 didn't meet Inclusion criteria

- 112: Other

- 0 Refused

1414 did not respond to offer of appoint.

251 DNA's From 551 scheduled appointments

70 no appointments made as recruitment numbers were met.

Allocation to Allen Carr ( $\mathrm{n=151}$ )

4 withdrew at 1 month

\section{Follow up}

1 month 41 (Phone/email follow up $\mathrm{N}=28$ )

3 months 70 (Phone/email follow up $\mathrm{N}=53$ )

6 months 79 (Phone/email follow up $\mathrm{N}=60$ )

12 months 88 (Phone/email follow up $\mathrm{N}=68$ )

\title{
Analysis
}

${ }^{1}$ Sex used as an example (male/female) but other PROGRESS characteristics could be used 
149 included in

analysis

0a Excluded

151 included in

analysis

0a Excluded

${ }^{a}$ Zero excluded as intention to treat analysis was used and so failure to attend was deemed as failing to quit.

${ }^{b}$ All phone and email follow up contacts were included in the complete case analysis 


\section{Baseline Characteristics}

Baseline Characteristics of Participants by Treatment Groups

\begin{tabular}{|c|c|c|}
\hline & $\begin{array}{l}\text { Quit.ie } \\
\text { (No.=149) }\end{array}$ & AC $($ No.=151) \\
\hline Female, No. (\%) & $68(45.6)$ & $67(44.4)$ \\
\hline Age, median (IQR) & $44.0(38.0-51.0)$ & $44.0(36.0-52.0)$ \\
\hline Initial weight, median (IQR), kg & $80.8(69.0-93.9)$ & $79.8(69.4-91.7)$ \\
\hline $\begin{array}{l}\text { Post-secondary and higher education, No. } \\
(\%)\end{array}$ & $104(69.8)$ & 105 (69.5) \\
\hline Baseline $\mathrm{CO}$ reading, mean (SD), ppm & $20.4(10.5)$ & $22.1(11.6)$ \\
\hline \multicolumn{3}{|l|}{ Time to first cigarette, No (\%) } \\
\hline$<=5$ mins & $42(28.2 \%)$ & $56(37.1 \%)$ \\
\hline 6-30 mins & $66(44.3 \%)$ & $61(40.4 \%)$ \\
\hline$>31$ mins & $41(27.5 \%)$ & $34(22.5 \%)$ \\
\hline Prior use of e-cigarettes, No. (\%) & $72(48.3 \%)$ & 75 (49.7\%) \\
\hline \multicolumn{3}{|l|}{ Previous quit attempts, No. (\%) } \\
\hline None & $6(4.2 \%)$ & $4(2.7 \%)$ \\
\hline 1 to 3 & $63(43.8 \%)$ & $69(46.3 \%)$ \\
\hline 4 to 9 & $61(42.4 \%)$ & $59(39.6 \%)$ \\
\hline 10 and over & $14(9.7 \%)$ & 17 (11.4\%) \\
\hline $\begin{array}{l}\text { No of cigarettes smoked per day, median } \\
\text { (IQR) }\end{array}$ & $20.0(15.0-22.0)$ & $20.0(15.0-25.0)$ \\
\hline $\begin{array}{l}\text { How many years are you smoking, median } \\
\text { (IQR) }\end{array}$ & $28.0(22.0-34.0)$ & $26.0(20.0-35.0)$ \\
\hline Readiness to quit score, median (IQR) & $27.0(24.5-29.0)$ & $27.0(25.0-29.0)$ \\
\hline
\end{tabular}


Outcome Measures

Quit rates at 1, 3, 6 and 12 months, No. (\%)

\begin{tabular}{|c|c|c|c|}
\hline & $\begin{array}{l}\text { Quit.ie } \\
\text { (No.=149) }\end{array}$ & $\begin{array}{l}\text { Allen Carr } \\
(\text { No.=151) }\end{array}$ & P value ${ }^{a}$ \\
\hline 1 month & $30(20.1 \%)$ & 57 (37.7\%) & 0.0004 \\
\hline 3 month & 22 (14.8\%) & $41(27.2 \%)$ & 0.004 \\
\hline 6 month & $23(15.4 \%)$ & 35 (23.2\%) & 0.045 \\
\hline 12 month & 17 (11.4\%) & 33 (21.9\%) & 0.008 \\
\hline
\end{tabular}




\section{Adverse Events}

The only reported adverse effect was one person in the AC treatment who went to see her doctor because of Nicotine withdrawal symptoms; she was prescribed a Nicotine patch and recovered completely.

There were no other reported side effects in this study. 